\title{
O ensino do design de tipos nas universidades públicas brasileiras: mapeamento e apontamentos
} The teaching of type design in Brazilian public universities: mapping and notes

\author{
Luiza Falcão Soares Cunha, Solange Coutinho \& Isabella Ribeiro Aragão
}

tipografia, ensino, fontes de texto, universidade

\begin{abstract}
A presente pesquisa visou explorar o escopo do ensino do design de tipos no ambiente universitário público brasileiro por meio de mapeamento das disciplinas relacionadas à área dentro desse perfil de Instituição de Ensino Superior (IES). Os procedimentos metodológicos utilizados foram a pesquisa documental para mapear os cursos, a aplicação de questionários para entender como a tipografia se insere nos perfis curriculares da IES abordadas pela pesquisa, e as entrevistas semiestruturadas com os professores de tipografia dos cursos selecionados. Seus resultados apontam que apesar da tipografia ser abordada em grande parte dos cursos de design de maneira transversal, ainda não existe um consenso quanto a existência de uma disciplina obrigatória nas matrizes curriculares dos cursos. No tocante às disciplinas de design de tipos, foi constatado que apenas 17 do total de 68 componentes curriculares relacionados ao ensino de conteúdos tipográficos abordam especificamente o design de tipos. A pesquisa também revelou que os recursos existentes nas Universidades públicas brasileiras são satisfatórios para uma disciplina inicial de design de tipos.
\end{abstract}

\section{typography, teaching, text fonts, university}

\begin{abstract}
The aim of the present research was to explore the sphere of teaching type design within the Brazilian public university environment. The objectives were to map the disciplines related to the area within this profile of higher education institutions (HEI), and to understand the main characteristics. The methodological procedures used were documentary research to map the courses, applying questionnaires to understand how the typography is inserted in the curricular profiles of the HEl addressed by the research, and semi-structured interviews with the typography teachers of the selected courses that teach type design for text. The results indicate that although typography is addressed by a most design courses transversally, there is no consensus regarding the existence of a compulsory subject in the curricular matrices of the courses. With regard to type design disciplines, it was found that only 17 of the 68 curricular components related to the teaching of typographic contents specifically address type design. The research also revealed that the resources available in Brazilian public universities are satisfactory for an initial discipline of type design.
\end{abstract}

\section{Introdução}

As possibilidades de configurações de uma situação de ensino dedicada ao design de tipos são distintas, e podem variar em relação aos conteúdos abordados, conhecimentos transmitidos e habilidades desenvolvidas pelos discentes. Cada uma das situações de ensino possui um objetivo pré-determinado que deve ser atingido com os recursos disponíveis e a duração pretendida. $O$ docente responsável por conduzir a dinâmica deve perceber tais características e planejar as aulas de acordo com a conjuntura existente. O presente artigo explora o escopo do ensino do design de tipos no ambiente universitário público brasileiro, e possui como objetivos mapear as disciplinas relacionadas à área e entender suas principais características. O estudo faz parte de uma pesquisa de doutorado que busca propor um modelo para o ensino do desenho de fontes de texto aplicável no contexto das disciplinas dos cursos de Bacharelado em Design das universidades públicas brasileiras.

O desenho de fontes de texto foi selecionado como foco para essa pesquisa por possuir no seu processo projetual os preceitos comuns a qualquer projeto de design de tipos e possibilitar,

Anais do 9 CIDI e 9 CONGIC

Luciane Maria Fadel, Carla Spinillo, Anderson Horta, Cristina Portugal (orgs.)

Sociedade Brasileira de Design da Informação - SBDI Belo Horizonte | Brasil | 2019

ISBN $978-85-212-1728-2$
Proceedings of the 9th CIDI and 9th CONGIC

Luciane Maria Fadel, Carla Spinillo, Anderson Horta, Cristina Portugal (orgs.)

Sociedade Brasileira de Design da Informação - SBDI Belo Horizonte | Brazil | 2019

ISBN 978-85-212-1728-2 
através do seu aprendizado, projetos mais simples e também os mais complexos. As disciplinas de design de tipos das universidades públicas brasileiras foram escolhidas para compor esse estudo devido a uniformidade das suas características contextuais, o que possibilita uma maior compreensão do objeto de estudo.

Para tanto, foi realizado um levantamento dos cursos de Bacharelado em Design, Design Gráfico, Design Visual, Comunicação Visual e Desenho Industrial das universidades públicas brasileiras, bem como das disciplinas de tipografia ministradas nesse perfil de Instituição de Ensino Superior (IES), além da identificação de quais delas lecionam o design de tipos para texto. Também buscou-se compreender como se estruturam tais disciplinas através do entendimento dos elementos que as integram, tais como o perfil do docente, o uso de modelos de ensino e as suas características estruturais - salas de aula, títulos disponíveis nas bibliotecas, laboratórios de informática, softwares especializados -, a fim de detectar qual a estrutura satisfatória e possível para o ensino do design de tipos dentro desse contexto, bem como quais os principais requisitos que um modelo de ensino do desenho de caracteres tipográficos de texto deve cumprir e conter.

Os procedimentos metodológicos utilizados foram a pesquisa documental para mapear os cursos, a aplicação de questionários com os coordenadores para entender como a tipografia se insere nos perfis curriculares da IES abordadas pela pesquisa, e as entrevistas semiestruturadas com os professores de tipografia dos cursos selecionados para compor 0 estudo.

\section{Breve descrição do ensino do Design no Brasil}

O marco do início do ensino superior em design no Brasil é a fundação da ESDI - Escola Superior de Desenho Industrial, no Rio de Janeiro, em 1963. Bonfim (1978) pontua que essa referência é simbólica, uma vez que iniciativas anteriores já almejavam o ensino do design em solo brasileiro, tais como o IAC-MASP ou a Escola Técnica de Criação (ETC) no Museu de Arte Moderna do Rio de Janeiro (MAM-RJ). No entanto, a ESDI forneceu um caráter institucional ao Design jamais visto até então: a instituição buscava construir um espaço capaz de estimular a produção de uma identidade nacional para os produtos e para a comunicação visual, além de apresentar o design ao público, legitimando assim a nova profissão no Brasil (Niemeyer, 2007).

A ESDI foi responsável pela consolidação no ensino do design no Brasil: afinal, foi a primeira Instituição a oferecer educação em design a nível de graduação, e, portanto, a formar os primeiros profissionais da área. A escola foi de extrema importância para o desenvolvimento do design e para a institucionalização do seu ensino, que até então era realizado em cursos de menor duração e com propostas curriculares mais simplificadas. O currículo da Instituição, baseado na estrutura de ensino da Escola de UIm, foi a referência para os primeiros cursos de graduação em design de Brasil, uma vez que não havia outros parâmetros curriculares.

O entendimento da construção do ensino superior a nível nacional se dá não apenas pelo conhecimento das iniciativas educacionais, mas também através do conhecimento da estruturação e das diretrizes do sistema de ensino nas quais tais cursos estão inseridos. No ano de 1961, a estruturação do sistema de cátedras foi abolida do ensino superior, com a formulação da primeira Lei de Diretrizes e Bases da Educação Nacional - LDB N.4024/61, que estabeleceu o currículo mínimo para o ensino superior, "com a finalidade de permitir maior flexibilidade na estrutura de ensino e expandir o acesso à educação, seguindo as diretrizes do desenvolvimento econômico pregado pela política nacional" (Carvalho, 2012 p.41). Desta forma, o Conselho Federal de Educação poderia definir os conteúdos dos cursos de graduação, fixando disciplinas obrigatórias - que constituiriam o currículo mínimo -, enquanto as Instituições de Ensino Superior eram responsáveis por complementar os currículos com disciplinas optativas - para formatar assim, o currículo pleno.

Contudo, de acordo com o Parecer CNE/CES 67/2003, as instituições evitavam a inovação dos Projetos Pedagógicos para conseguirem atender às disciplinas e cargas horárias detalhadas pelo currículo mínimo. Por não possuírem a liberdade de alterar as ementas das 
disciplinas do currículo mínimo, algumas instituições ficaram sobrecarregadas ao tentarem cumprir as disciplinas obrigatórias e os cursos acabaram engessados e pouco maleáveis.

Um conjunto de Pareceres (CES/CNE 0146/2002, 67/2003 e 0195/2003) teve a intenção de garantir a maleabilidade e a criatividade na concepção das estruturas dos cursos de graduação, uma vez que cada uma das IES ficaria mais responsável pelo escopo do curso. No design essa nova realidade representa uma grande mudança de paradigma, uma vez que finalmente os cursos poderiam se tornar mais alinhados à realidade da indústria e do mercado, tanto a nível nacional quanto local.

Especificamente no Parecer 0195/2003, que entrou em vigor no ano de 2004 e continua válido até o presente momento, fica explicitado que a designação Bacharelado em Design seria adotada em detrimento da designação Bacharelado em Desenho Industrial, vigente na época. É importante atentar que desde o ano de 2004, as universidades que oferecem cursos de Bacharelado em Design detêm a autonomia completa para definir quais serão as ênfases oferecidas, além de especificar quais serão os componentes curriculares dos cursos e como eles serão configurados. Ao observar a lista dos conteúdos definidos para o curso do Bacharelado em Design, não é possível achar uma menção clara e específica ao ensino da tipografia. No entanto, é possível inferir que dentro das definições dos conteúdos básicos relacionados à "comunicação e informação" ou dentro das definições dos conteúdos específicos relacionados à "comunicação visual"1 está contemplado o ensino dos conteúdos tipográficos.

De acordo com Farias et al. (2005), a tipografia esteve presente nos currículos de design no Brasil de maneira tecnicista e redutora, muitas vezes como um simples sinônimo da impressão com tipos móveis. Um indício desse fato pode ser encontrado na observação da estrutura curricular da ESDI, por exemplo, onde a tipografia figura como disciplina do setor de oficinas. A realidade da estruturação do ensino da tipografia em solo brasileiro vai de encontro a importância de tal questão, destacada por autores como Lupton (2006) e Heller (2004), que abordam a aprendizagem da tipografia como elemento essencial para a formação de qualquer designer gráfico. Esse fato é um reflexo de diversos fatores, dentro os quais se destacam o início tardio do estudo da tipografia e da produção de fontes no Brasil, bem como da produção de pesquisas na área.

A evolução das diretrizes do sistema de ensino superior em design apresentada anteriormente também influenciou na maneira como os cursos de graduação incluíram o estudo da tipografia nas matrizes curriculares através dos anos. Algumas instituições públicas, como a Universidade Federal de Pernambuco, já abordam o ensino do desenho tipográfico há mais tempo, ainda na década de 1970, com os exercícios de desenho manual propostos pelo professor Guilherme Cunha Lima (Silveira, 2014). No entanto, considerando que apenas a partir da década de 2000 as diretrizes curriculares se tornaram, de fato, mais maleáveis, a flexibilidade para inserção de conteúdos específicos como o design de tipos nos componentes curriculares dos cursos de design no Brasil ainda é recente.

Com o intuito de entender qual a realidade do ensino do design de tipos nas Universidades Públicas Brasileiras atualmente, foi realizada uma pesquisa para mapear os cursos que oferecem disciplinas dessa natureza e para entender as suas principais características, conforme será apresentado a seguir.

\section{Apontamentos sobre o ensino de design de tipos nas IES públicas}

A partir de uma pesquisa documental, foram mapeados os cursos presenciais de Bacharelado em Design, Design Gráfico, Design Visual, Comunicação Visual e Desenho Industrial nas universidades públicas brasileiras. Posteriormente, através da aplicação de questionários com os coordenadores dos cursos levantados, procurou-se entender sobre como a Tipografia se insere nas matrizes curriculares das IES mapeadas, quais são os cursos que oferecem

\footnotetext{
${ }^{1}$ Art.5ำ, I, do Parecer CNE/CES 0195/2003
} 
disciplinas específicas voltadas para o design de tipos em suas grades, e por fim, quem são os professores atuantes dentro da área nas universidades públicas brasileiras.

Em seguida foram aplicados novos questionários com os professores de tipografia mapeados nos questionários anteriores, com o intuito de catalogar quais deles exploram em suas disciplinas o design de tipos para texto. Por fim, foi realizada uma triagem dos professores que lecionam conhecimentos dessa natureza para que fosse possível realizar uma entrevista semiestruturada com os sujeitos selecionados. Aqui, destaca-se que a pesquisa buscou entender como se dá a dinâmica de ensino de tal conteúdo dentro das universidades públicas brasileiras, quais os conhecimentos transmitidos, quais as práticas pedagógicas mais utilizadas e quais as principais dificuldades encontradas por esses professores para o ensino do ofício.

\section{Mapeamento das disciplinas de tipografia dos cursos de Bacharelado em Design, Design Gráfico, Design Visual, Comunicação Visual e Desenho Industrial das universidades públicas brasileiras}

O ponto de partida dessa exploração foi a listagem de todas as Instituições públicas de Ensino Superior no Brasil que oferecem cursos presenciais de Bacharelado em Design, Design Gráfico, Design Visual, Comunicação Visual, ou Desenho Industrial, e que pudessem, consequentemente, oferecer disciplinas capazes de lecionar conteúdos relacionados ao design de tipos. Segundo o portal do Cadastro e-MEC de Instituições e Cursos de Educação Superior, existem 33 IES no perfil selecionado para essa pesquisa no Brasil, atualmente. Os questionários e entrevistas realizados com os coordenadores e professores desses cursos, revelaram que dentro desse universo existem 29 cursos $^{2}$ que oferecem disciplinas específicas ou relacionadas à tipografia (Figura 1).

Figura 1: Universidades públicas brasileiras da área que oferecem disciplinas relacionadas à tipografia em suas matrizes curriculares. Fonte: as autoras.

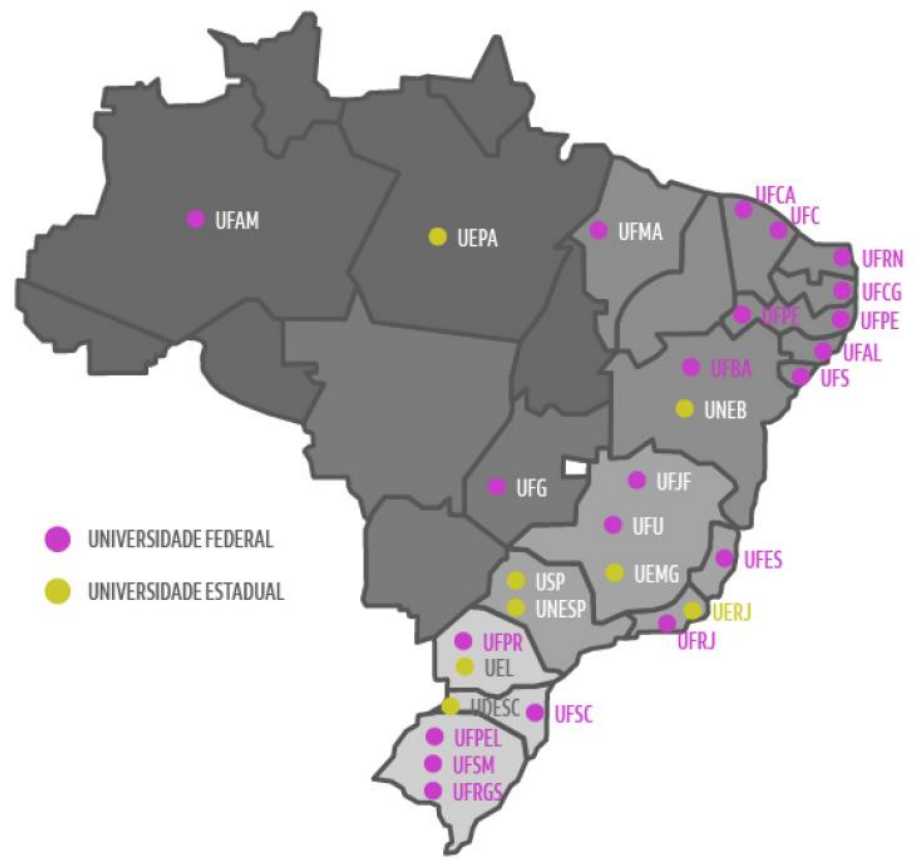

Foram encontradas, ao todo, 68 disciplinas relacionadas à área tipográfica nos cursos listados através dos procedimentos de pesquisa realizados. Destaca-se que o quantitativo de disciplinas explicitado anteriormente pode apresentar alguma variação, uma vez que, conforme foi mencionado por alguns coordenadores e professores, parte da teoria relacionada à ${ }^{2}$ São 29 cursos em 28 IES, uma vez que a UFPE possui dois cursos de Bacharelado em Design com grades
curriculares distintas. 
tipografia é pulverizada em várias disciplinas do curso de design, e não apenas nas que são dedicadas exclusivamente à área. A terminologia também é um fator que dificulta o entendimento do universo de tais componentes curriculares, pois recorrentemente tais disciplinas possuem nomes mais abrangentes e, portanto, sujeitos a diversas interpretações. Por fim, a dificuldade para obter acesso aos Projetos Pedagógicos dos Cursos, às suas grades curriculares e as ementas das disciplinas também dificultou a interpretação completamente fiel do conteúdo lecionado em tais situações de ensino. A lista apresentada a seguir é um panorama das disciplinas que abordam algum tipo de teoria relacionada à tipografia nos seus conteúdos programáticos ${ }^{3}$ (Figura 2).

Figura 2: Lista das disciplinas relacionadas à tipografia. Fonte: as autoras.

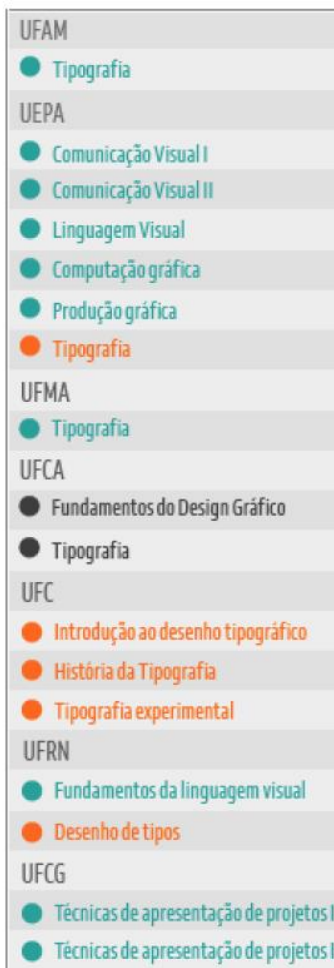

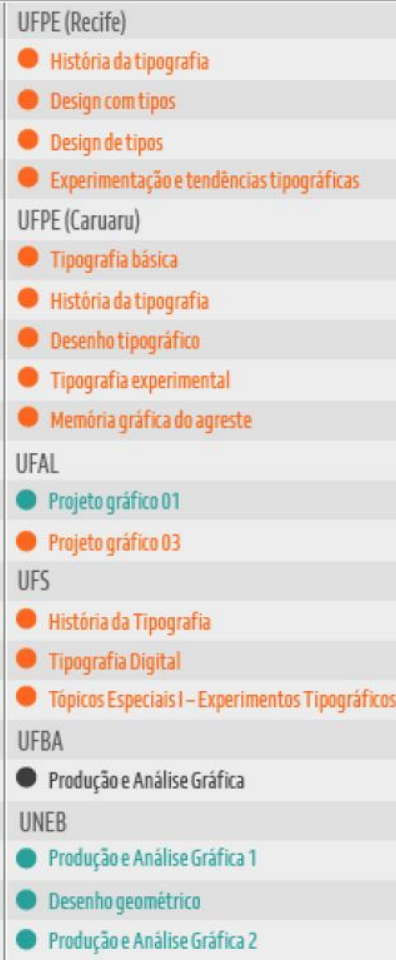

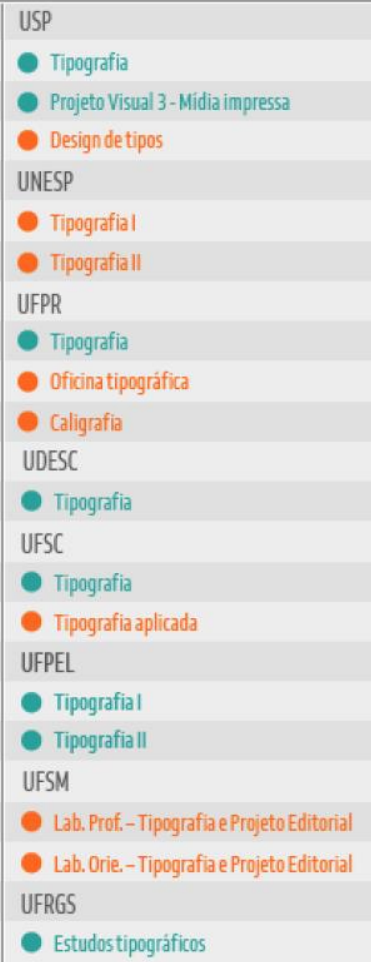

Estudostipográficos

A partir das respostas dos questionários realizados com os professores de tipografia e com os coordenadores dos cursos, foi percebido que apenas 17 dos componentes curriculares apresentados anteriormente se relacionam com o design de tipos: esse é o panorama do ensino o design de tipos no Brasil, dentro do âmbito de Instituições de Ensino Superior públicas, atualmente (Figura 3). Através da análise qualitativa dos questionários, foi percebido que nem todas as disciplinas citadas anteriormente estariam dentro do âmbito estudado por essa pesquisa: apenas 9 dos componentes curriculares abordam especificamente o desenho de fontes para texto (Figura 4). A pesquisa revelou que alguns dos componentes curriculares encontrados lecionam teorias relacionadas ao projeto de fontes de texto e realizam exercícios que poderiam ser aplicados nesse contexto, porém não é exigido que os discentes produzam desenhos próprios para uma fonte de texto.

\footnotetext{
${ }^{3}$ Informações sobre o caráter obrigatório ou optativo das disciplinas foram buscadas na pesquisa documental. As informações relacionadas às disciplinas da UFCA e da UFBA não foram encontradas.
} 
Figura 3: Lista das disciplinas relacionadas ao design de tipos. Fonte: as autoras.

\begin{tabular}{|c|c|c|c|}
\hline UFCA & UFPE (Recife) & UFG & UFSC \\
\hline - Fundamentos do Design Gráfico & - Designdetipos & - Projetotipográfico & - Tipografia \\
\hline - Tipografia & UFPE (Caruaru) & UFES & UFSM \\
\hline UFC & - História datipografia & - Gráfica1 1Tipografia) & - Lab. Prof.-Tipografia e Projeto Editoria \\
\hline - Introdução a a desenho tipográfico & Desenhotipográfico & - Design de Tipos Digitais & - Lab. Orie. - Tipografia e Projeto Editoria \\
\hline UFRN & UEMG & USP & UFPEL \\
\hline \multirow[t]{2}{*}{ - Desenhode tipos } & - Prática ProjetualI & - Tipografia & Tipografial \\
\hline & & - Designdetipos & \\
\hline
\end{tabular}

Figura 4: Lista das disciplinas relacionadas ao design de tipos para texto. Fonte: as autoras.

\begin{tabular}{|c|c|c|c|}
\hline UFC & UFPE (Recife) & UFG & USP \\
\hline - Introduçăo ao desenho tipográfico & Designdetipos & - Projeto tipogŕf́ico & - Designdetipos \\
\hline UFRN & UFPE (Caruaru) & UFES & UFSM \\
\hline \multirow[t]{2}{*}{ - Desenhodetipos } & - Históriada tipografia & Design de Tipos Digitais & - Lab. Prof.-Tipografia eProjeto Editorial \\
\hline & Desenhotipográfico & & L Lab. Orie,-Tipografia Projeto Editorial \\
\hline
\end{tabular}

\section{Características das disciplinas relacionadas ao design de tipos das universidades públicas brasileiras}

A fim de entender como funciona o ensino do conteúdo em tais situações de ensino, foram realizadas entrevistas semiestruturadas via videoconferência com alguns dos professores responsáveis pelas disciplinas levantadas. Inicialmente, foram identificadas mais informações sobre tais disciplinas nos Projetos Pedagógicos dos Cursos para que, posteriormente, a escolha pudesse ser realizada de acordo com a disponibilidade dos sujeitos de interesse. Os docentes consultados por esse estudo foram a professora Priscila Farias da Universidade de São Paulo (USP), o professor Buggy da Universidade Federal do Ceará (UFC), o professor Volnei Matté da Universidade de Santa Maria (UFSM) e o professor Ricardo Esteves da Universidade Federal do Espírito Santo (UFES). Os apontamentos a seguir são frutos dessa coleta de dados ${ }^{4}$.

De uma maneira geral, os cursos de Bacharelado em Design possuem alguns componentes curriculares obrigatórios que são considerados básicos para todos os alunos do curso, e nos quais são abordados conhecimentos indispensáveis para qualquer especialização do design. Também são oferecidos, por volta da segunda metade do curso, alguns componentes curriculares de caráter optativo, mais específicos de acordo com as ênfases oferecidas pelo curso em questão: tais componentes curriculares tendem a possuir caráter prático. É neste segundo grupo que se inserem as disciplinas relacionadas ao design de tipos.

Hoje em dia, o design de tipos não se configura como uma linha de formação específica nos cursos de design do Brasil. As entrevistas realizadas com os docentes de tipografia indicam que os conhecimentos da área do design tipográfico são muito complexos e específicos para serem ensinados em profundidade dentro de um curso de Bacharelado em Design. No entanto, parte de tais conhecimentos - em especial os que se relacionam à fase de desenho dos caracteres tipográficos -, excede o processo projetual do design de tipos e pode ser aplicado em outros processos projetuais tais como na configuração de artefatos editoriais ou no projeto de identidades visuais. Assim, eles consideram que disciplinas dedicadas ao desenho de tipos devem fazer parte das matrizes curriculares dos cursos de design.

${ }^{4}$ Os professores da Universidade Federal de Pernambuco foram excluídos dessa fase da pesquisa pois a pesquisa está sendo realizada no Programa de Pós-graduação em Design da instituição. 
Foi diagnosticado que existe a necessidade de um componente curricular obrigatório de tipografia nos primeiros anos dos cursos de design que possuam ênfase no design gráfico. Dessa forma, os principais conceitos da área seriam lecionados a todos os alunos do curso, uma vez que a tipografia é um elemento básico para o exercício da linguagem visual. Além de fornecer uma base de tipografia para os alunos que pretendem cursar disciplinas de design de tipos no futuro, tal nivelamento é fundamental para o trabalho com design gráfico. Foi observado que apenas metade dos cursos estudados possuem tais componentes curriculares. De acordo com os professores, os cursos que não oferecem disciplinas obrigatórias de tipografia possuem outros componentes curriculares obrigatórios que trabalham teorias introdutórias à área tipográfica transversalmente. $O$ fato tem um impacto direto no nivelamento do conhecimento dos alunos que cursam as disciplinas optativas de design de tipos, e é um fator que deve ser considerado na concepção de um modelo de ensino do desenho de tipos para esse tipo de curso.

O entendimento de teorias básicas da tipografia é fundamental para que o discente compreenda a complexidade de um projeto tipográfico e para que possua o conhecimento necessário para executá-lo. O tempo se destaca como um fator importante nessa questão, e precisa ser considerado dentro do contexto de proposição de um modelo de ensino aplicável às disciplinas de design de tipos das graduações em design: tais disciplinas possuem em média 60 horas semestrais dedicadas ao design de tipos, portanto não há tempo para um grande número de aulas expositivas exclusivamente teóricas. Por ser tratar de um componente curricular de caráter prático explícito, os docentes possuem a expectativa de que os alunos já possuam conhecimentos teóricos básicos, indispensáveis para os projetos tipográficos. Dessa forma, as disciplinas são planejadas para cumprir uma carga teórica pequena, caracterizada por uma revisão dos principais conceitos, seguida por uma série de atividades projetuais.

A pesquisa revelou que o foco das disciplinas de design de tipos nos cursos de graduação em design não é necessariamente a produção de fontes finalizadas, mas sim o entendimento do projeto tipográfico, o estímulo do olhar, o treino do desenho manual e digital do tipo, e o espaçamento básico dos caracteres. Detalhes mais avançados como kerning, hitting e funções opentype não são tão explorados pelos professores nem tampouco exigidos dos alunos. Como tais disciplinas não conseguem abarcar e enfatizar as fases projetuais que se seguem ao desenho e ao espacejamento básico dos caracteres, os docentes se utilizam de algumas estratégias para que os discentes mais interessados no assunto possam explorar mais a área dentro da graduação, tais como o trabalho de conclusão de curso.

No tocante à estrutura necessária para uma situação de ensino que se dedique ao design de tipos nas graduações em design, foi percebido que é necessário haver uma sala com mesas para desenho, equipamentos de projeção e som, e se possível, um laboratório de informática equipado com softwares de desenho vetorial e de geração de fontes. Foi percebido que as instituições de ensino superior públicas brasileiras oferecem a estrutura básica. Os softwares de geração de fontes viáveis para utilização nas universidades foram o FontForge - por ser um software livre -, e o Fontlab, pois algumas instituições possuem licenças.

As universidades públicas brasileiras possuem uma bibliografia básica de tipografia disponível para os alunos nas suas bibliotecas. No que diz respeito a obras mais específicas e mais recentes do design de tipos, como os livros Designing Type e Como criar tipos: do esboço à tela, há uma carência de títulos, oriunda tanto do contexto de publicação das obras no Brasil quanto do contexto que permeia a compra de obras bibliográficas nas IES abordadas por essa pesquisa: nem sempre existe verba disponível para adquirir as obras recém-lançadas pelas editoras. Os docentes tentam adquirir obras mais direcionadas ao design tipográfico e disponibilizá-las aos alunos, através de recursos externos ou até mesmo através de esforços pessoais. A editora Estereográfica foi citada recorrentemente por ser a editora a lançar a maior quantidade de títulos específicos sobre tipografia nos últimos anos no Brasil; no entanto, a compra desses livros pelas universidades públicas ainda não é uma realidade.

Materiais multimídias, tais como vídeos de palestras ou de entrevistas com designers de tipos, se mostraram de grande relevância enquanto recursos didáticos para disciplinas de design de tipos, como uma maneira de aproximar a academia dos profissionais atuantes no mercado de trabalho. Grande parte de tais materiais está disponível gratuitamente em diversos 
websites, e pode ser utilizado para fins didáticos nas aulas. Atualmente, é possível perceber que a documentação do conhecimento especializado no design de tipos não se encontra apenas nos livros e produções científicas, mas também em outros canais tais como blogs especializados e em plataformas como o Youtube. Outros recursos frequentemente utilizados pelos professores e alunos são os materiais básicos de desenho, tais como folhas de papel sulfite, folhas de papel manteiga, lápis e borrachas. Dessa forma, entende-se que os recursos necessários para uma disciplina de design de tipos são completamente viáveis dentro da conjuntura das universidades públicas brasileiras.

Por se tratar de uma situação de ensino de caráter prático, as disciplinas da graduação em design dedicadas ao projeto tipográfico se dedicam bastante à realização de exercícios que trabalham a capacidade de percepção dos alunos acerca do desenho de tipos. As orientações dos projetos e a avaliação coletiva em sala de aula, onde todos os alunos podem ver e comentar sobre o trabalho dos demais participantes, também são práticas didáticas recorrentes e se mostraram de grande importância para a dinâmica da disciplina, bem como para o desenvolvimento dos projetos e a aprendizagem dos alunos. Além das atividades, que possuem como meta exercitar fatores específicos relacionados ao design de tipos, os discentes também são direcionados a projetarem uma fonte. Por se tratar de um projeto de complexidade mais alta, grande parte do tempo da disciplina é reservado aos seus procedimentos. O produto requerido é, geralmente, o software da fonte no qual devem constar os caracteres alfabéticos mais básicos, tais como caixa alta e caixa baixa. O design de tipos para texto é proposto por grande parte dos professores, porém não é exigido um projeto com um nível de refinamento muito alto devido ao caráter iniciante da disciplina.

Os docentes consultados por essa pesquisa indicam que os resultados projetuais dos alunos são satisfatórios: grande parte das fontes cumprem o básico esperado, e algumas se destacam por sua qualidade formal (Figuras 5 e 6). Apesar de se tratar de uma disciplina optativa, o engajamento dos alunos é variável. No entanto, os professores consideram que existe uma boa adesão dos discentes aos exercícios propostos e à disciplina, uma vez que o índice de evasão é pequeno. É possível observar nas fontes desenvolvidas uma aderência à proposta de projeto de uma fonte de texto, fato que demonstra que disciplinas de design de tipos que trabalhem o desenho de tipografias de texto são viáveis do ponto de vista de aprendizado e produção de fontes simples.

Figura 5: Trabalhos desenvolvido na disciplina Laboratório Profissionalizante da UFSM. Fonte: cedido pelo docente Volnei Matté (2018).
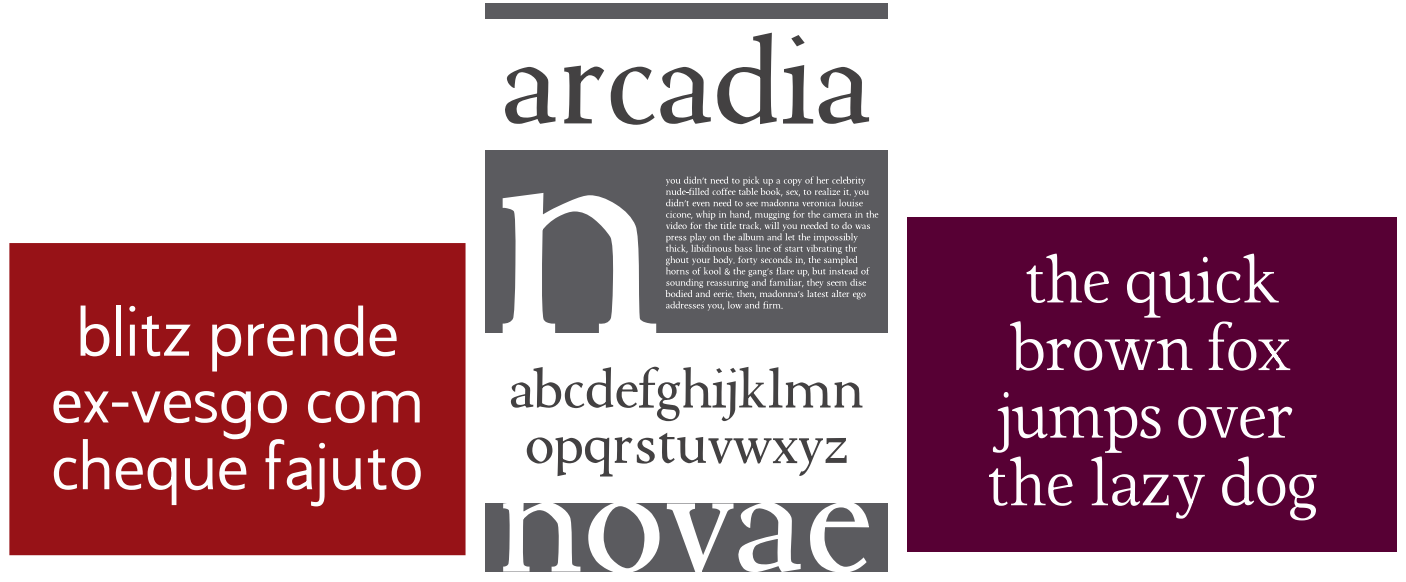

Figura 6: Trabalhos desenvolvido na disciplina Design de Tipos da UFES. Fonte: cedido pelo docente Ricardo Esteves (2018). 
The quick brown fox jumps over the lazy dog Foxy parsons quiz and cjole the lovably dim wikigirlWatch Jeopady Alex Trebeks fun TV quiz game How razorbackjumping frogs can level six piqued gymnasts All questions asked by five watched ex Puxa o Rebatedor de Me

0 fantástico
tipo beta
em corpo realmente
GRANDE

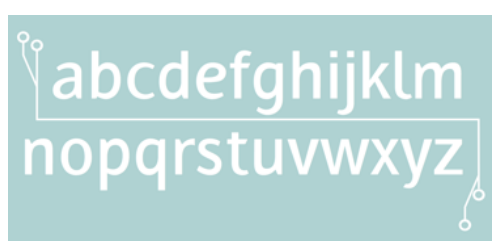

A utilização de um modelo de ensino pré-definido ainda é um ponto flutuante entre os professores de tipografia das universidades públicas brasileiras. Parte deles afirma usar modelos e procedimentos específicos, desenvolvidos por eles ou por outros profissionais da área, e outros não utilizam um modelo de ensino. No entanto, uma questão destacada por vários professores é a alternância da teoria com a prática através da realização de exercícios ou de projetos. Portanto, reafirma-se que o design de tipos é uma disciplina de caráter prático bastante proeminente, fato que se assemelha intrinsecamente com o contexto educacional do início do ofício, caracterizado pela relação mestre-aprendiz.

\section{Considerações finais}

Este artigo visou estudar e entender o universo de ensino do design de tipos dentro dos cursos de Bacharelado em Design das universidades públicas brasileiras. A institucionalização e a regulamentação do ensino em design no Brasil ainda são bastante recentes: tal fato possui grande influência na realidade de ensino da tipografia nos cursos atualmente. Ao longo da pesquisa, houve uma dificuldade de entendimento das matrizes curriculares dos cursos de design das IES públicas brasileiras e dos conteúdos lecionados nas disciplinas que as compõem. Nesse sentido, as respostas qualitativas dos questionários e das entrevistas realizadas foram mais esclarecedoras do que os dados recolhidos através da pesquisa documental, que muitas vezes foram de difícil interpretação.

A pesquisa revelou que as disciplinas de design de tipos dos cursos de Bacharelado em Design das IES públicas brasileiras se configuram como disciplinas optativas. A existência de uma disciplina básica de tipografia nos primeiros semestres dos cursos faz-se necessária para fornecer um nivelamento dos conceitos básicos para os alunos, uma vez que não existe muito tempo para aulas exclusivamente teóricas na disciplina de design de tipos: no entanto, apenas uma parte dos cursos levantados oferecem componentes curriculares obrigatórios dedicados apenas à tipografia.

Foi percebido que o número de disciplinas dedicadas ao design de tipos nas universidades públicas brasileiras ainda pode ser considerado pequeno, frente ao quantitativo de cursos de design existentes. Ao observar o montante que aborda especificamente o design de tipos de texto, fica claro que esse ainda é um assunto pouco abordado nos cursos de Bacharelado em Design. O projeto de uma fonte dessa natureza pode não ser viável dentro de uma única disciplina dedicada ao design de tipos. Por outro lado, os professores afirmam que estruturam toda a situação de ensino para abarcar os conhecimentos relacionados ao design de tipos de texto, e de uma maneira geral, os alunos possuem liberdade para escolher o tipo de fontes que irão projetar ao longo da situação de ensino.

Foi constatado que a principal tática didática dos professores de tipografia para lecionar o design de tipos é a constante alternação da teoria com a prática. A realização de pequenos exercícios de baixa complexidade após a apresentação da teoria foi uma prática bastante citada pelos docentes entrevistados. Orientações individuais e coletivas dos projetos também se mostraram como práticas recorrentes e bem-sucedidas dentro das situações de ensino estudadas.

Apesar de entender que o design de tipos de texto pode se configurar como uma área muito específica dentro do design, e, portanto, ter seu estudo mais adequado para cursos de pósgraduação, o presente estudo constatou que a inserção de uma disciplina elementar dedicada ao assunto no grupo das disciplinas optativas dos cursos de design é de grande valia para os 
alunos que desejam trabalhar não apenas com o projeto de fontes, mas também com a área do design gráfico. O presente estudo revelou que o fator fundamental para a inserção da disciplina em um maior número de cursos é a existência de um professor da área no corpo docente, uma vez que os demais recursos básicos necessários já são difundidos nas IES.

A partir das informações recolhidas na pesquisa, espera-se desenvolver um modelo de ensino do desenho dos caracteres tipográficos que possa ser aplicado em disciplinas dos cursos de design das universidades públicas brasileiras para facilitar e difundir o ensino do design de tipos.

\section{Referências}

Bonfim, G. A. (1978). Desenho Industrial: uma proposta de reformulação do currículo mínimo. Dissertação (Programa de Engenharia da COPPE) - Universidade Federal do Rio de Janeiro, Rio de Janeiro (RJ).

Brasil. (1961). Lei no 4.024, de 20 de dezembro de 1961. Fixa as diretrizes e bases da educação nacional. Lei de Diretrizes e Bases da Educação-LDB. Brasília. Disponível em: <http://www.planalto.gov.br/ccivil_03/LEIS/L4024.htm >, 26/06/2019.

Brasil. (2002). Parecer Conselho Nacional de Educação/Câmara de Educação Superior $n$. 0146/2002. Diretrizes Curriculares Nacionais dos cursos de Graduação em Direito, Ciências Econômicas, Administração, Ciências Contábeis, Turismo, Hotelaria, Secretariado Executivo, Música, Dança, Teatro e Design. Brasília. Disponível em: <http://portal.mec.gov.br/cne/arquivos/pdf/CES0146.pdf>, 26/06/2019.

Brasil. (2003a). Parecer Conselho Nacional de Educação/Câmara de Educação Superior $n$. 67/2003. Referencial para as Diretrizes Curriculares Nacionais - DCN dos Cursos de Graduação. Brasília. Disponível em: <portal.mec.gov.br/cne/arquivos/pdf/2003/pces067_03.pdf>, 26/06/2019.

Brasil. (2003b). Parecer Conselho Nacional de Educação/Câmara de Educação Superior $n$. 0195/2003. Diretrizes Curriculares Nacionais dos cursos de graduação em Música, Dança, Teatro e Design. Brasília. Disponível em: < http://portal.mec.gov.br/cne/arquivos/pdf/2003/pces195_03.pdf>, 26/06/2019.

Brasil. (2004). Resolução CNE/CES 5/2004. Aprova as Diretrizes Curriculares Nacionais do Curso de Graduação em Design e dá outras providências. Diário Oficial da União, Brasília, DF, 15 mar. 2004, Seção 1, p. 24. Republicada no Diário Oficial da União, Brasília, DF, 1 abr. 2004, Seção 1, p. 19. Disponível em: < http://portal.mec.gov.br/cne/arquivos/pdf/rces05_04.pdf>, 26/06/2019.

Buggy, L. (2018). Entrevista. [out 2018]. Entrevistador: Luiza Falcão Soares Cunha. Recife/PE.

Carvalho, A. P. C. de. (2012). O ensino paulistano de design: a formação das escolas pioneiras. Dissertação (Mestrado em Design e Arquitetura) - Universidade de São Paulo, São Paulo.

Couto, R. M. S. (2008). Escritos Sobre Ensino de Design no Brasil. Rio de Janeiro: Rio Books.

Farias, P. L.; Gouveia, A. P. \& Oliveira, J. (2005). Tipografia e design gráfico: um relato de uma experiência didática. Anais do $3^{\circ}$ Congresso Internacional de Pesquisa em Design CIPED, Rio de Janeiro (RJ).

Farias, P. L. (2018). Entrevista. [nov 2018]. Entrevistador: Luiza Falcão Soares Cunha. Recife/PE.

Esteves, R. (2018). Entrevista. [out 2018]. Entrevistador: Luiza Falcão Soares Cunha. Recife/PE.

Heller, S. (2004). The education of a typographer. New York: Altworth Press.

Lupton, E. (2006). Pensar com tipos. São Paulo: Cosac Naify. 
Falcão, L., Coutinho, S. \& Aragão, I. | O ensino do design de tipos nas universidades públicas brasileiras: mapeamento e apontamentos

Matté, V. (2018). Entrevista. [set 2018]. Entrevistador: Luiza Falcão Soares Cunha. Recife/PE.

Ministério da educação. (2018). Sistema e-MEC: Instituições de Educação Superior e Cursos Cadastrados. Disponível em: <https://emec.mec.gov.br>, 10/07/2018.

Niemeyer, L. (2007). Design no Brasil: origens e instalação. Rio de Janeiro: 2AB.

Silveira, A. (2014). Design de tipos em Pernambuco: estudo de uma situação de ensino. Dissertação (Mestrado em Design) - Universidade Federal de Pernambuco, Recife/PE.

\section{Sobre o(a/s) autor(a/es)}

Luiza Falcão Soares Cunha; Doutoranda, UFPE, Brazil <luizafsc@gmail.com>

Solange Galvão Coutinho; Ph.D, UFPE, Brazil <sol2015ufpe@gmail.com>

Isabella Ribeiro Aragão; Doutora, UFPE, Brazil <isabella.aragao@gmail.com> 